\title{
CASE REPORT | INFLAMMATORY BOWEL DISEASE
}

\section{Infliximab-Induced Aseptic Meningitis in a Patient with Crohn's Disease}

\author{
Zachary Junga, MD', Brett Theeler, $M D^{2}$, and Manish Singla, MD' \\ 'Gastroenterology Service, Department of Medicine, Walter Reed National Military Medical Center, Bethesda, MD \\ ${ }^{2}$ Neurology Service, Department of Medicine, Walter Reed National Military Medical Center, Bethesda, MD
}

\begin{abstract}
Infliximab is an anti-tumor necrosis factor $\alpha$ (TNF $\alpha$ ) monoclonal antibody that treats moderate-to-severe Crohn's disease. In rare cases, infliximab has been associated with drug-induced aseptic meningitis. We present a 46year-old woman with migraines and inflammatory Crohn's colitis treated with intravenous infliximab and methotrexate. She developed nuchal rigidity, photophobia, and headache 2 days after each of her infliximab infusions, with symptom resolution 1 week post-infusion. Her exam, imaging, and cerebrospinal fluid analysis were consistent with drug-induced aseptic meningitis. She discontinued infliximab and started vedolizumab with continued remission of her Crohn's disease.
\end{abstract}

\section{INTRODUCTION}

Infliximab is an anti-tumor necrosis factor $\alpha$ (TNF $\alpha$ ) monoclonal antibody that treats moderate-to-severe Crohn's disease. ${ }^{1,2}$ In rare cases, infliximab has been associated with drug-induced aseptic meningitis (DIAM), a potentially dangerous complication. ${ }^{3,4}$ There have been only 7 previously reported cases..$^{5-11}$

\section{CASE REPORT}

We present a 46-year-old woman with migraines and inflammatory Crohn's colitis. Her Crohn's colitis was treated initially with adalimumab, but this was discontinued due to arthralgias and auto-antibody formation. She achieved clinical remission on a brief steroid taper with maintenance intravenous infliximab $5 \mathrm{mg} / \mathrm{kg}$ every 8 weeks and subcutaneous methotrexate $25 \mathrm{mg}$ weekly. After her steroids were tapered during infliximab induction and a maintenance dose, she began to have nuchal rigidity, photophobia, and headache 2 days after each of her infliximab infusions. Her symptoms routinely resolved 1 week post-infusion. Her neurological examination and magnetic resonance imaging of the brain and cervical spine were normal. A lumbar puncture during symptoms (4 days after infliximab infusion) showed an elevated cerebrospinal fluid (CSF) white blood cell count (32 cells/ $\mu \mathrm{L}$ ) with neutrophil-predominance (55\%), normal protein, and negative Gram stain and culture. The CSF analysis and temporal association with infusion were consistent with DIAM. She discontinued infliximab, and her symptoms resolved after 2 weeks. She was started on vedolizumab with continued remission of her Crohn's disease.

\section{DISCUSSION}

There have been 7 reported cases of DIAM attributed to infliximab: 5 cases of patients with inflammatory bowel disease, 1 patient with rheumatoid arthritis, and 1 patient with psoriasis. Onset of symptoms ranged from hours to 2 weeks after infusion, with most cases having symptoms start within 1 week of infusion of infliximab. Symptoms varied widely, but headache and fever were the most common symptoms, and neck stiffness, arthralgias, and myalgias were present in most cases. All patients were more than 30 years old. Doses of infliximab varied but were mostly 5

ACG Case Rep J 2018;5:e48. doi:10.14309/crj.2018.48. Published online: June 20, 2018.

Correspondence: Zachary Junga, Gastroenterology Service, Department of Medicine, Walter Reed National Military Medical Center, 8901 Rockville Pike, Bethesda, MD 20889 (jungaz@gmail.com). 
$\mathrm{mg} / \mathrm{kg}$, with 1 patient receiving an escalated dose of $6.25 \mathrm{mg} /$ $\mathrm{kg}$ and another receiving $3 \mathrm{mg} / \mathrm{kg}$. Symptom resolution ranged from less than 5 days in the majority of patients to 2-8 weeks after cessation of infliximab.

Although DIAM is often a diagnosis of exclusion, the following criteria must be met: temporal relationship with drug intake; CSF pleocytosis ( $>5$ cells $/ \mathrm{mm}^{3}$ ) which can be neutrophil-predominant; negative cultures; resolution of the syndrome on drug withdrawal; and absence of another explanation for meningitis. 3.4 DIAM may be secondary to a delayed hypersensitivity reaction, or it may be due to peripheral inhibition of TNF $\alpha$ spurring enhanced action of brainderived TNF $\alpha$ leading to meningeal inflammation. Infliximabinduced aseptic meningitis is a rare complication of infliximab therapy, but it is important for gastroenterologists to be aware of this potentially severe side effect. Recurrent DIAM can lead to long-term sequelae, including increased intracranial pressure, cranial neuropathies, and chronic head and neck pain.

Our patient's symptoms did not develop until after her steroid course was tapered. Whether the onset of symptoms was related to the steroids being removed and they were having a protective effect is debatable, but it can give us an idea of possible symptomatic treatment if symptoms are slow to resolve in future patients. The benefit of corticosteroids in the treatment of aseptic meningitis is limited to case reports of aseptic meningitis from intravenous immunoglobulin. ${ }^{12-13}$ In both patients treated with corticosteroids, symptoms resolved within 1-2 days, which suggests that steroids may be a beneficial treatment. Our case gives potential insight into the pathophysiology of infliximab-induced DIAM being an immune-mediated process.

\section{DISCLOSURES}

Author contributions: Z. Junga wrote the article and is the article guarantor. B. Theeler and M. Singla edited the article.
Financial disclosure: None to report.

Informed consent was obtained for this case report.

Received March 1, 2018; Accepted May 2, 2018

\section{REFERENCES}

1. Lichtenstein GR, Hanauer SB, Sandborn WJ, Practice Parameters Committee of the American College of Gastroenterology. Management of Crohn's disease in adults. Am J Gastroenterol. 2009;104(2):465-83.

2. Hanauer SB, Feagan BG, Lichtenstein GR, et al. Maintenance infliximab for Crohn's disease: The ACCENT randomized trial. Lancet. 2002;359 (9317):1541-9.

3. Moris G, Garcia-Monco JC. The challenge of drug-induced aseptic meningitis. Arch Intern Med. 1999;159:1185-94.

4. Moris G, Garcia-Monco JC. The challenge of drug-induced aseptic meningitis revisited. JAMA Intern Med. 2014;174(9):1511-2.

5. Hegde N, Gayomali C, Rich MW. Infliximab-induced headache and infliximab-induced meningitis: Two ends of the same spectrum? South Med J. 2005;98(5):564-6.

6. Manthey C, Lohse AW, Pace A. Case report of aseptic meningitis in a patient with Crohn's disease under infliximab therapy. Inflamm Bowel Dis. 2011;17(2):E10.

7. Marotte H, Charrin JE, Miossec P. Infliximab-induced aseptic meningitis. Lancet. 2001;358:1784.

8. Quispel R, van der Worp HB, Pruissen M, Schipper ME, Oldenburg B. Fatal aseptic meningoencephalitis following infliximab treatment for inflammatory bowel disease. Gut. 2006;55(7):1056.

9. Rushikesh S, Shah M, Bansal N, Manocha D. Infliximab-induced aseptic meningitis. Am J Emerg Med. 2014;32(12):1560.

10. Matsuura-Otsuki Y, Hanafusa T, Yokozeki H, Watanabe K. Infliximabinduced aseptic meningitis during the treatment of psoriatic arthritis. Case Rep Dermatol. 2017;9:26-9.

11. Tissot B, Visée S, Pilette C, Prophette B, Puechal X. Lymphocytic meningitis with infliximab for ulcerative colitis. Gastoenterol Clin Biol. 2006;30 (12):1420-2.

12. Rao SP, Teitlebaum J, Miller ST. Intravenous immune globulin and aseptic meningitis. Am J Dis Child. 1992;146(5):539-40.

13. Ellis RJ, Swendson MR, Bajorek J. Aseptic meningitis as a complication of intravenous immunoglobulin therapy for myasthenia gravis. Muscle Nerve. 1994;17(6):683-4. 